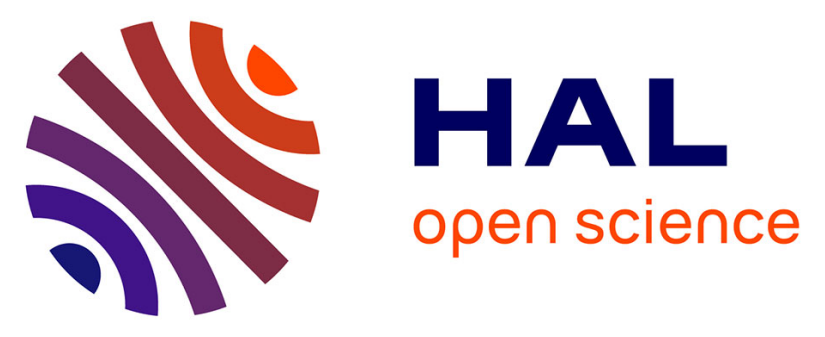

\title{
Association of peripartum management and high maternal blood loss at cesarean delivery for placenta accreta spectrum (PAS): A multinational database study \\ Alexander Schwickert, Heleen Beekhuizen, Charline Bertholdt, Karin Fox, Gilles Kayem, Olivier Morel, Marcus Rijken, Vedran Stefanovic, Gita Strindfors, Alexander Weichert, et al.
}

\section{To cite this version:}

Alexander Schwickert, Heleen Beekhuizen, Charline Bertholdt, Karin Fox, Gilles Kayem, et al.. Association of peripartum management and high maternal blood loss at cesarean delivery for placenta accreta spectrum (PAS): A multinational database study. Acta Obstetricia et Gynecologica Scandinavica, 2021, 100 (S1), pp.29-40. 10.1111/aogs.14103 . hal-03259459

\section{HAL Id: hal-03259459 \\ https://hal.univ-lorraine.fr/hal-03259459}

Submitted on 15 Jun 2021

HAL is a multi-disciplinary open access archive for the deposit and dissemination of scientific research documents, whether they are published or not. The documents may come from teaching and research institutions in France or abroad, or from public or private research centers.
L'archive ouverte pluridisciplinaire HAL, est destinée au dépôt et à la diffusion de documents scientifiques de niveau recherche, publiés ou non, émanant des établissements d'enseignement et de recherche français ou étrangers, des laboratoires publics ou privés.

\section{(이)(\$)}

Distributed under a Creative Commons Attribution - NonCommercial - NoDerivatives| 4.0 


\title{
Association of peripartum management and high maternal blood loss at cesarean delivery for placenta accreta spectrum (PAS): A multinational database study
}

\author{
Alexander Schwickert ${ }^{1}$ () | Heleen J. van Beekhuizen ${ }^{2}$ () | Charline Bertholdt ${ }^{3,4}$ (๑) |

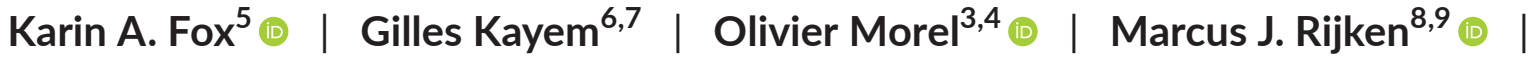

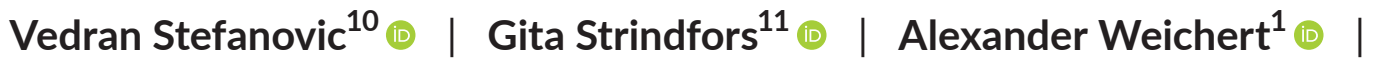 \\ Katharina Weizsaecker ${ }^{1}$ (1) | Thorsten Braun ${ }^{1,12}$ (]) | on behalf of the International Society \\ for Placenta Accreta Spectrum (IS-PAS)*

\footnotetext{
${ }^{1}$ Department of Obstetrics, Charité - Universitätsmedizin Berlin, corporate member of Freie Universität Berlin, Humboldt-Universität zu Berlin, and Berlin Institute of Health, Berlin, Germany

${ }^{2}$ Department of Gynecological Oncology, Erasmus MC Cancer Center, Rotterdam, The Netherlands

${ }^{3}$ Women's Division, Nancy Regional and University Hospital Center (CHRU), Université de Lorraine, Nancy, France

${ }^{4}$ Diagnosis and International Adaptive Imaging (IADI), Inserm, Université de Lorraine, Nancy, France

${ }^{5}$ Division of Maternal-Fetal Medicine, Department of Obstetrics and Gynecology, Baylor College of Medicine, Houston, TX, USA

${ }^{6}$ Trousseau Hospital, Assistance Publique - Hôpitaux de Paris, Sorbonne University, Paris, France

${ }^{7}$ Obstetrical, Perinatal and Pediatric Epidemiology (EPOPé) Research Team, center of Research in Epidemiology and Statistics U1153, Inserm, Université de Paris, Paris, France

${ }^{8}$ Division Women and Baby, Department of Obstetrics, University Medical center Utrecht, Utrecht University, Utrecht, The Netherlands

${ }^{9} J u l i u s$ Global Health, The Julius center for Health Sciences, University Medical center Utrecht, Utrecht, The Netherlands

${ }^{10}$ Department of Obstetrics and Gynecology, Fetomaternal Medical Center, Helsinki University Hospital and University of Helsinki, Helsinki, Finland

${ }^{11}$ Department of Obstetrics and Gynecology, South General Hospital, Stockholm, Sweden

${ }^{12}$ Department of 'Experimental Obstetrics', Charité - Universitätsmedizin Berlin, corporate member of Freie Universität Berlin, Humboldt-Universität zu Berlin, and Berlin Institute of Health, Berlin, Germany
}

\section{Correspondence}

Alexander Schwickert, Charité -

Universitätsmedizin Berlin, Klinik für

Geburtsmedizin, Augustenburger Platz 1,

13353 Berlin, Germany.

Email: alexander.schwickert@charite.de

\begin{abstract}
Introduction: Placenta accreta spectrum (PAS) carries a high burden of adverse maternal outcomes, especially significant blood loss, which can be life-threatening. Different management strategies have been proposed but the association of clinical risk factors and surgical management options during cesarean delivery with high blood loss is not clear.

Material and methods: In this international multicenter study, 338 women with PAS undergoing cesarean delivery were included. Fourteen European and one non-European
\end{abstract}

Abbreviations: aOR, adjusted odds ratio; CD, cesarean delivery; Cl, confidence interval; cOR, crude odds ratio; FIGO, International Federation of Gynecology and Obstetrics; IQR, interquartile range; IS-PAS, International Society for Placenta Accreta Spectrum; PAS, placenta accreta spectrum; TXA, tranexamic acid.

*See Appendix 1

This is an open access article under the terms of the Creative Commons Attribution-NonCommercial-NoDerivs License, which permits use and distribution in any medium, provided the original work is properly cited, the use is non-commercial and no modifications or adaptations are made.

(c) 2021 The Authors. Acta Obstetricia et Gynecologica Scandinavica published by John Wiley \& Sons Ltd on behalf of Nordic Federation of Societies of

Obstetrics and Gynecology (NFOG). 
center (USA) provided cases treated retrospectively between 2008 and 2014 and prospectively from 2014 to 2019. Peripartum blood loss was estimated visually and/or by weighing and measuring of volume. Participants were grouped based on blood loss above or below the 75 th percentile $(>3500 \mathrm{ml}$ ) and the 90 th percentile $(>5500 \mathrm{ml})$.

Results: Placenta percreta was found in $58 \%$ of cases. Median blood loss was $2000 \mathrm{ml}$ (range: 150-20 $000 \mathrm{ml}$ ). Unplanned hysterectomy was associated with an increased risk of blood loss $>3500 \mathrm{ml}$ when compared with planned hysterectomy (adjusted OR [aOR] 3.7 [1.5-9.4], $p=0.01$ ). Focal resection was associated with blood loss comparable to that of planned hysterectomy (crude OR 0.7 [0.2-2.1], $p=0.49$ ). Blood loss $>3500 \mathrm{ml}$ was less common in patients undergoing successful conservative management (placenta left in situ, aOR 0.1 [0.0-0.6], $p=0.02$ ) but was more common in patients who required delayed hysterectomy (aOR 6.5 [1.7-24.4], $p=0.001$ ). Arterial occlusion methods (uterine or iliac artery ligation, embolization or intravascular balloons), application of uterotonic medication or tranexamic acid showed no significant effect on blood loss $>3500 \mathrm{ml}$. Patients delivered by surgeons without experience in PAS were more likely to experience blood loss $>3500 \mathrm{ml}$ (aOR 3.0 [1.4-6.4], $p=0.01$ ). Conclusions: In pregnant women with PAS, the likelihood of blood loss $>3500 \mathrm{ml}$ was reduced in planned vs unplanned cesarean delivery, and when the surgery was performed by a specialist experienced in the management of PAS. This reinforces the necessity of delivery by an expert team. Conservative management was also associated with less blood loss, but only if successful. Therefore, careful patient selection is of great importance. Our study showed no consistent benefit of other adjunct measures such as arterial occlusion techniques, uterotonics or tranexamic acid.

\section{KEYWORDS}

abnormally invasive placenta, cesarean, high-risk pregnancy, hysterectomy, placenta, postpartum hemorrhage, uterine scar

\section{1 | INTRODUCTION}

Although maternal mortality rates are declining, the increasing incidence of cesarean delivery $(C D)$ has resulted in an increase in placenta accreta spectrum (PAS), or abnormally invasive placenta, adversely impacting maternal outcomes globally. ${ }^{1,2}$ PAS describes the clinical disease spectrum in which a placenta does not separate spontaneously at delivery and cannot be removed without causing abnormal and potentially life-threatening bleeding due to varying degrees of placental invasion into or through the myometrium. ${ }^{3,4}$ Although still relatively rare, PAS carries a disproportionate risk of severe maternal morbidity and mortality, and contributes considerably to the proportion of postpartum hemorrhage with hysterectomy. ${ }^{5}$ Not only is PAS a heterogeneous disease spectrum, but management of pregnancies with PAS varies widely across centers. Management strategies include delivery by planned cesarean hysterectomy, focal myometrial resection and conservative management leaving the placenta in situ after delivery, with or without adjunctive measures such as arterial embolization or planned delayed hysterectomy. ${ }^{6}$

Various efforts have been made to identify associations between clinical management and maternal blood loss, morbidity and

\section{Key message}

Planned procedures, including hysterectomy and focal resection for placenta accreta spectrum (PAS), are associated with lower blood loss than unplanned hysterectomies. Peripartum blood loss is less when cesarean delivery is managed by a surgeon or surgical team specialized in PAS.

mortality in PAS. Most studies are conducted by single centers, with limited data and generalizability to guide the optimal management of this condition. In an attempt to address these problems, international groups, including the International Society for PAS (IS-PAS) and the International Federation of Gynaecology and Obstetrics (FIGO), have published proposals for standardization of imaging ${ }^{7,8}$ IS-PAS has joined together specifically to pool international multi-center data to identify outcomes across various centers and identify research gaps.

We aimed to determine which epidemiologic factors and which management factors were associated with high and extraordinarily high peripartum blood loss in CD complicated by PAS. 


\section{2 | MATERIAL AND METHODS}

\section{1 | Patient recruitment}

The IS-PAS database contains both retrospectively and prospectively collected obstetric and surgical data of pregnant patients $>14$ gestational weeks with suspected and/or pathologically proven PAS. Cases from April 2008 to December 2013 were registered retrospectively in the database. Cases from 2014 to 2019 were collected prospectively. In total, 442 cases were included in the database. ${ }^{9}$

\subsection{Exclusion criteria}

Of the 442 cases in the IS-PAS database, 32 cases of women with normal placentation (antenatally suspected PAS with normal placental separation, ie "false positive cases") were excluded from this analysis. A further 26 cases not delivered by CD (vaginal delivery $[n=17]$ and termination of pregnancy [ $n=9]$ ) were excluded. Thirtyone cases were excluded due to missing information on operative management and 15 cases due to missing data on blood loss. In total, 338 cases were included and analyzed (Figure 1, Table S1).

\section{3 | Measurement of blood loss and clinical classification of PAS}

Each center recorded blood loss using their own standardized local protocol, whether by quantified measurement or visual estimation. The degree of invasion was classified based on the IS-PAS Grading system ${ }^{7}$ originally proposed in 2015 and upon which the more

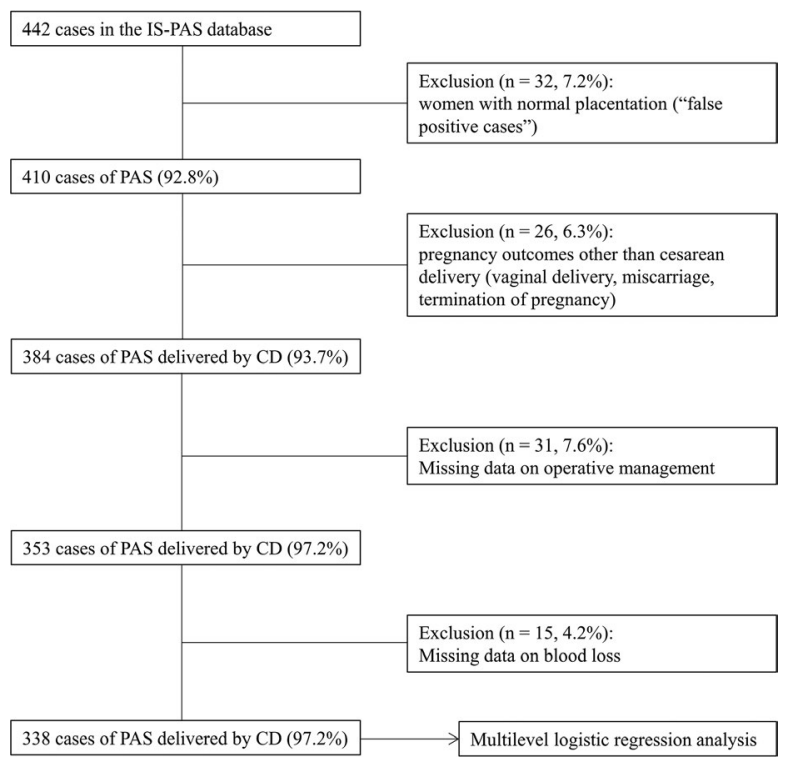

FIGURE 1 Selection of cases. CD, cesarean delivery; PAS, placenta accreta spectrum recently published FIGO Clinical Classification system was based. ${ }^{8,10}$ The publication by Braun et al includes further details.

\section{4 | Data collection}

Data were collected both retrospectively (cases managed from 2008 to 2014) and prospectively (2014-2019) via chart review using a standardized, secured and password-protected online data collection platform (FetView, Zeitgeist Health SE). ${ }^{9}$ Participants were grouped based on blood loss in this study above the 75th percentile of our cohort (>3500 $\mathrm{ml}$ ) and blood loss above the 90th percentile (>5500 ml) (Appendix S1).

The following factors were investigated with regard to their association with peripartum blood loss:

- Number of previous CD

- Presence of placenta previa

- Antenatal PAS diagnosis (antenatally suspected vs unsuspected PAS)

- IS-PAS grades of invasion 2-6

- Degree of urgency of delivery

- Experience of the surgeon: specialist in PAS vs gynecologist/obstetrician with no particular training in PAS (definition: an expert is a person with significant experience in PAS and a high level of knowledge and/or skills relating to the condition) ${ }^{11}$

- Operative management

- Type of management (planned hysterectomy, unplanned hysterectomy, focal resection, placenta left in situ with uncomplicated resorption, placenta in situ followed by planned or unplanned delayed hysterectomy)

- Position of the uterine incision (fundal, lower transverse, transverse above placenta)

- Measures to support uterine contraction/aid blood clotting

- Oxytocin (prophylactic administration - before increased blood loss occurred; therapeutic administration - after increased blood loss occurred)

- Tranexamic acid (TXA; prophylactic administration - before increased blood loss occurred; therapeutic administration after increased blood loss occurred)

- Prostaglandin F2 $\alpha /$ E2/E1 (prophylactic administration - before increased blood loss occurred; therapeutic administration - after increased blood loss occurred)

- Intrauterine balloon (prophylactic administration - before increased blood loss occurred; therapeutic administration after increased blood loss occurred)

- Perioperative occlusion of uterine blood supply (no other types of occlusion reported):

- Pelvic arterial embolization

- Intravascular balloon (femoral or iliac)

- Uterine artery ligation

- Internal iliac artery ligation 


\subsection{Statistical analyses}

Univariate and multivariate analyses were used to test associations with blood loss $>3500$ and $>5500 \mathrm{ml}$. A multilevel logistic regression model served to control for possible variation between participating centers (Appendix S1). The 15 centers were defined as a second level variable. As a first step, the influence on peripartum blood loss was calculated for each first level variable separately (univariate analysis). In analyses comparing planned management approaches, planned hysterectomy was the reference category for operative management, as this is the most commonly used, definitive immediate treatment of placenta accreta spectrum. ${ }^{12}$ Crude odds ratios (cOR) with $95 \%$ confidence interval $(95 \% \mathrm{Cl})$ were calculated for all results. Next, a multivariate regression analysis was carried out, in cluding variables that had been identified as having a significant effect in univariate analysis ( $p \leq 0.05)$. Multivariate analyses yielded adjusted odds ratios (aOR) with $95 \% \mathrm{Cl}$.

\section{6 | Ethical approval}

Local Ethical Committee/IRB approval and Data Use Agreements were obtained according to local policies. Details of these can be found in the online Supporting Information contained in the second Commentary of this supplement. ${ }^{9}$

\section{3 | RESULTS}

\section{1 | Demographic, clinical and outcome characteristics of enrolled women}

Table 1 shows the demographic data of the analyzed cases. Placenta percreta (PAS grade 4-6) was present in 58\% of cases. Overall, median blood loss was $2000 \mathrm{ml}$ (range 150-20 000 ml, Figure 2A). Perioperative occlusion of uterine blood supply was used in $28 \%$ (95/338) of cases. Among these cases, it was used therapeutically in $46 \%(44 / 95)$ of cases, that is, after occurrence of high blood loss. The most commonly used prophylactic intervention was intravascular balloon placement $(48 / 338 ; 14 \%)$. Overall, a reduction in total blood loss was seen over time (Figure $2 \mathrm{~B}$ ).

\section{2 | Factors not significantly associated with high peripartum blood loss}

Tables 2 and 3 show the results of the multilevel logistic regression analyses. Blood loss $>3500 \mathrm{ml}$ or $>5500 \mathrm{ml}$ did not differ between centers (inter-center variance 1.3 [0.3-4.9], $p=0.15$ ). The number of previous $C D$, the presence of placenta previa and antenatal diagnosis of PAS showed no association with perioperative blood loss. No difference in blood loss was noted between focal resection and planned hysterectomy. Focal resection was performed in 26 cases: three times in PAS grade 2, two times in PAS grade 3, 18 times in PAS grade 4, one time in PAS grade 5, two times in PAS grade 6. Univariate analyses did not yield significant correlations between measures to promote uterine contraction (administration of uterotonics, intrauterine balloon) or blood loss $>3500 \mathrm{ml}$. No difference in blood loss was seen with prophylactic use of TXA (univariate analyses: >3500 ml: cOR 0.5 [0.2-1.2], $p=0.12 ;>5500 \mathrm{ml}$ : cOR 0.3 [0.11.5], $p=0.14$; prophylactic TXA] $\mathrm{n}=53$, [no TXA] $\mathrm{n}=182$. Blood loss $>5500 \mathrm{ml}$ was not significantly associated with type or timing of surgical intervention (aOR 2.4 [0.9-6.6], $p=0.08$ for unplanned hysterectomy; aOR 0.9 [0.1-6.5], $p=0.92$ for delayed hysterectomy). Univariate analyses showed increased association between cases with blood loss $>3500$ and blood loss $>5500 \mathrm{ml}$ in emergent $\mathrm{CD}$ vs scheduled CD (cOR 3.5 [1.2-10.2], $p=0.02$ and cOR 2.6 [1.0-6.8], $p=0.04$, respectively), but not after multivariate analysis. Univariate analyses did not yield significant correlations between perioperative occlusion of uterine blood supply available in our dataset (uterine artery embolization, femoral balloon, uterine artery ligation, internal iliac artery ligation) and blood loss $>3500$ or $>5500 \mathrm{ml}$.

\subsection{Factors associated with significantly increased risk for high peripartum blood loss}

Compared with planned hysterectomy, unplanned hysterectomy was associated with significantly higher odds of blood loss $>3500$ $\mathrm{ml}$ (aOR 3.7 [1.5-9.4], $p=0.01$ ). The association with blood loss $>5500 \mathrm{ml}$ did not hold in multivariate analysis (aOR 2.4 [0.9-6.6], $p=0.08$ ). Delayed hysterectomy was associated with a significantly higher likelihood of total blood loss $>3500 \mathrm{ml}$ (aOR 6.5 [1.7-24.4], $p=0.001$ ). Placenta percreta with parametrial invasion (Grade 6) showed a trend to a higher proportion of cases with blood loss $>3500 \mathrm{ml}$ (aOR 3.4 [0.9-12.3], $p=0.06$ ), with insignificant results in terms of blood loss $>5500 \mathrm{ml}$ (aOR 1.9 [0.6-7.0], $p=0.32$ ). There was a positive correlation between therapeutic internal iliac artery ligation and blood loss $>3500 \mathrm{ml}$ (cOR 4.4 [1.2-16.2], $p=0.03$ ). Manual removal of placenta was attempted significantly less frequently in the blood loss $>3500 \mathrm{ml}$ group and only performed in lower PAS grades of invasion (grades 2 and 3; aOR 0.2 [0.1-0.6], $p=0.01)$.

\subsection{Factors associated with significantly reduced risk for high peripartum blood loss}

Interestingly, fewer cases with blood loss $>3500 \mathrm{ml}$ occurred for placenta percreta grade 4 in multivariate analysis (aOR 0.4 [0.1$0.9] ; p=0.04$, reference category: PAS grade of invasion 2). This was more pronounced for blood loss $>5500 \mathrm{ml}$ (aOR 0.2 [0.1-0.8], $p=0.01$ ). Leaving the placenta in situ was associated with fewer cases of blood loss $>3500 \mathrm{ml}$ but only if it was successful without further interventions (aOR 0.1 [0.0-0.6], $p=0.02$ ). Delivery by a surgeon experienced in PAS was strongly related to blood loss $>3500$ 
TABLE 1 Demographic, clinical and outcome characteristics of enrolled women $(n=338)$

\begin{tabular}{|c|c|c|}
\hline Variable & $n=338$ & $\begin{array}{l}\% \text { of } \\
\text { cases }\end{array}$ \\
\hline
\end{tabular}

Characteristics at enrolment

Maternal age, years ${ }^{\mathrm{a}}$

$34.6(34.1-35.2)$

Gravidity $^{b}$

$3(2-5)$

Parity ${ }^{b}$

$2(1-3)$

Number of prior cesarean deliveries ${ }^{c}$

338

100

0 (no prior cesareans)

56

1 prior cesarean

135

$\geq 2$ prior cesareans

147

298

Placenta previa ${ }^{c}$

Outcome characteristics

Gestational age at delivery in weeks ${ }^{\text {b }}$

Cesarean delivery ${ }^{c}$

$36(34-37)$

PAS diagnosed antenatally ${ }^{c}$

100

Operative management ${ }^{c}$

Planned cesarean hysterectomy

Unplanned cesarean hysterectomy

Focal resection

Leaving placenta in situ

Leaving placenta in situ + delayed HE

Manual removal of placenta

PAS Grading ${ }^{c}$

Grade of invasion 2

Grade of invasion 3

Grade of invasion 4

Grade of invasion 5

Grade of invasion 6

Blood loss in $\mathrm{ml}$ (range) (b,c $^{\mathrm{b}}$

Blood loss $>3500 \mathrm{ml}$

Blood loss $<3500 \mathrm{ml}$

Blood loss $>5500 \mathrm{ml}$

Blood loss $<5500 \mathrm{ml}$

Transfused red packed cells (range) (b,c $^{\mathrm{b}}$

$0-1$ red packed cells

2-4 red packed cells

More than four red packed cells

Oxytocin ${ }^{c}$

No oxytocin (reference)

Prophylactic oxytocin

Therapeutic oxytocin

Prostaglandin ${ }^{c}$

No prostaglandin (reference)

Prophylactic prostaglandin

Therapeutic prostaglandin
182

\section{1}

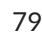

306

91

54

12

8

7

4

15

79

62

123

48

26

2000

(150-20 000)

92

246

33

305

2 (0-108)

153

86

99

$321^{\mathrm{d}}$

156

113

52

$336^{\mathrm{d}}$

275

13

48
TABLE 1 (Continued)

\begin{tabular}{|c|c|c|}
\hline Variable & $n=338$ & $\begin{array}{l}\% \text { of } \\
\text { cases }\end{array}$ \\
\hline Tranexamic acid ${ }^{c}$ & $330^{d}$ & 98 \\
\hline No tranexamic acid (reference) & 182 & 54 \\
\hline Prophylactic tranexamic acid & 53 & 16 \\
\hline Therapeutic tranexamic acid & 95 & 28 \\
\hline Urgency of cesarean delivery ${ }^{c}$ & $337^{d}$ & 100 \\
\hline $\begin{array}{l}\text { At a time to suit the woman and } \\
\text { maternity team (elective) }\end{array}$ & 228 & 68 \\
\hline $\begin{array}{l}\text { Needing early delivery but no } \\
\text { maternal or fetal compromise }\end{array}$ & 44 & 13 \\
\hline $\begin{array}{l}\text { Maternal or fetal compromise } \\
\text { which is not immediately } \\
\text { life-threatening }\end{array}$ & 50 & 15 \\
\hline $\begin{array}{l}\text { Immediate threat to life of woman } \\
\text { or fetus (crash) }\end{array}$ & 15 & 5 \\
\hline Grade of surgeon ${ }^{c}$ & $325^{d}$ & 96 \\
\hline Specialist in PAS (reference) & 249 & 77 \\
\hline No specialist & 76 & 23 \\
\hline Position of uterine incision ${ }^{c}$ & $323^{d}$ & 96 \\
\hline Lower transverse (reference) & 98 & 30 \\
\hline Fundal & 157 & 49 \\
\hline Transverse above placenta & 68 & 21 \\
\hline Intravascular balloon ${ }^{c}$ & $337^{d}$ & 100 \\
\hline No balloon (reference) & 285 & 84 \\
\hline Prophylactic & 48 & 14 \\
\hline Therapeutic & 4 & 1 \\
\hline Embolization $^{c}$ & $335^{d}$ & 99 \\
\hline No embolization (reference) & 319 & 94 \\
\hline Prophylactic & 2 & 1 \\
\hline Therapeutic & 14 & 4 \\
\hline Uterine artery ligation ${ }^{c}$ & 338 & 100 \\
\hline No ligation (reference) & 321 & 95 \\
\hline Prophylactic & 1 & 0 \\
\hline Therapeutic & 16 & 5 \\
\hline Internal iliac artery ligation ${ }^{c}$ & 338 & 100 \\
\hline No ligation (reference) & 328 & 97 \\
\hline Prophylactic & 0 & 0 \\
\hline Therapeutic & 10 & 3 \\
\hline Intrauterine balloon ${ }^{c}$ & $334^{d}$ & 99 \\
\hline No balloon (reference) & 289 & 86 \\
\hline Prophylactic & 9 & 3 \\
\hline Therapeutic & 36 & 11 \\
\hline Maternal death & 0 & 0 \\
\hline
\end{tabular}

Abbreviations: PAS, placenta accreta spectrum.

${ }^{a}$ Data presented as mean $(95 \% \mathrm{CI})$.

${ }^{\mathrm{b}}$ Data presented as median (IQR).

${ }^{\mathrm{C}}$ Data presented as $n(\%)$.

${ }^{d}$ Case numbers that do not add up to 338 cases (100\%) denote missing data. 

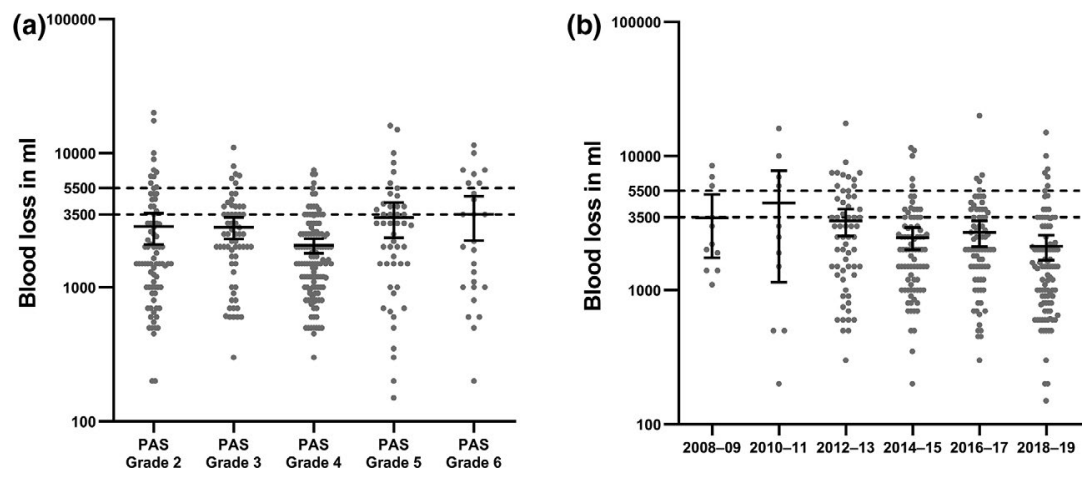

FIGURE 2 Scatter plots showing blood loss according to PAS grade of invasion (A) and the year of delivery (B). Mean blood loss in ml ( \pm 95\% Cl) per grade: Grade 2: 2834 (2085-3583), Grade 3: 2808 (2289-3327), Grade 4: 2048 (1792-2304), Grade 5: 3311 (2342-4279), Grade 6: 3508 (2230-4785). Non-significant tendency toward lower blood loss in PAS Grade 4 ( $p=0.05$, Kruskal-Wallis test). PAS Grade 1 is not shown as it denotes normal placentation. $3500 \mathrm{ml}$ (75th percentile) and $5500 \mathrm{ml}$ (90th percentile) are marked to illustrate the thresholds used to compare cases with high peripartum blood loss

and $>5500 \mathrm{ml}$ (multivariate analyses: $>3500 \mathrm{ml}$ : aOR 3.0 [1.4-6.4], $p=0.01 ;>5500 \mathrm{ml}$ : aOR 4.0 [1.6-9.9], $p=0.003$, respectively).

\section{4 | DISCUSSION}

As reported elsewhere, planned cesarean hysterectomy remains the most common treatment method used within our multi-center international cohort. ${ }^{12,13}$ Conservative management, whether by leaving the placenta in situ or via partial myometrial resection has been shown to be feasible, with favorable short-term maternal outcomes and subsequent fertility. ${ }^{14-16}$ To date, it is unclear whether conservative approaches confer a significant reduction in peripartum blood loss. Within this cohort, leaving the placenta in situ was associated with lower odds of blood loss $>3500 \mathrm{ml}$ compared with planned cesarean hysterectomy when successful (62\% of cases, $n=24)$. When hysterectomy was performed as a delayed procedure (38\% of cases, $n=15$, including planned and unplanned), it was associated with higher odds of total blood loss $>3500 \mathrm{ml}$ or $>5500 \mathrm{ml}$. Additionally, leaving the placenta in situ confers risks of secondary postpartum hemorrhage, sepsis or disseminated intravascular coagulation. ${ }^{15-17}$ A multicenter retrospective case series by Palacios-Jaraquemada et al on outcomes after resective-reconstructive techniques has compared the blood loss of 326 patients with different topographic forms of PAS. ${ }^{14}$ The median blood loss of the 338 cases in our study was $2000 \mathrm{ml}$ (interquartile range [IQR] 1000-3500 ml). This is similar to, but with a wider range, compared with the results of PalaciosJaraquemada et al. ${ }^{14}$ Although this was not the subject of this study, it seems possible that specific hemostasis over pedicles that irrigate the placenta and the invaded area can help to reduce blood loss $>3500 \mathrm{ml}$.

Interestingly, the odds for blood loss $>3500 \mathrm{ml}$ were similar between focal resection and planned hysterectomy. This suggests that focal resection is a feasible option for women who want to keep their uterus, when the location and size of placental invasion permits this procedure.
There was no significant association of blood loss $>3500$ and $>5500 \mathrm{ml}$ and the use of adjunctive measures to reduce blood loss, including use of the anti-fibrinolytic medication (TXA). Therapeutic use of TXA positively correlated with blood loss $>3500 \mathrm{ml}$ (OR 2.4 [1.4-4.2; $p=0.001$ ). This positive correlation likely reflects the indication of ongoing bleeding rather than a failure of efficacy. Overall, the prophylactic use of adjunctive measures was relatively infrequent within the cohort. In the TRAAP study, a large multicenter study from France published in 2018, no difference in the rate of blood loss $<500 \mathrm{ml}$ was seen between women receiving oxytocin alone or oxytocin plus prophylactic TXA. ${ }^{18}$ One recently published double-blinded randomized controlled study (46 patients) demonstrated that TXA during surgery for PAS (without specification of the grade of invasiveness) was effective in significantly reducing the intraoperative blood loss compared with the placebo group. ${ }^{19}$ Welldesigned and appropriately powered studies to address the safety and efficacy of adjunctive measures are essential to understand their utility. Newer studies suggest that arterial occlusion of the aorta reduces blood loss in PAS patients. ${ }^{20,21}$ In a recent randomized controlled trial that included 100 women with placenta previa and different grades of PAS, the use of intraoperative bilateral internal iliac artery balloon occlusion did not reduce the number of units of packed red blood cells transfused or otherwise improve outcomes. ${ }^{22}$

Even placenta accreta or increta (lower grades) can be associated with blood loss $>3500$ and $>5500 \mathrm{ml}$. Conversely, in placenta percreta (higher grades), blood loss $>3500 \mathrm{ml}$ occurred more frequently in cases involving placental invasion into other organs, whereas placenta percreta without invasion of other organs was associated with lower blood loss. One reason might be that PAS Grade 4 can be easily detected both on antenatal ultrasound as well as intraoperatively, so that manual removal of the placenta was not attempted, yet compared with PAS infiltrating urinary bladder or other organs (PAS Grade 5 or 6), the surgical complexity in PAS Grade 4 is manageable. Lesser degrees of invasion may permit partial placental separation and bleeding from the placental bed or greater willingness on the part of the provider to attempt manual placental extirpation, 
TAB LE 2 Multilevel logistic regression analysis of maternal peripartum blood loss $>3500 \mathrm{ml}$

\begin{tabular}{|c|c|c|c|c|c|}
\hline Variable & $\begin{array}{l}N \text { (total } \\
n=338)\end{array}$ & \multicolumn{4}{|c|}{ Blood loss $>3500 \mathrm{ml}$ (75. P.) } \\
\hline Number of previous cesarean deliveries & 338 & $1.1(0.9-1.3)$ & 0.53 & & $\mathrm{n} / \mathrm{i}$ \\
\hline Operative management & & & $<0.001$ & & $<0.001$ \\
\hline Planned caesarean hysterectomy (reference) & 182 & & & & \\
\hline Unplanned caesarean hysterectomy & 40 & $3.9(1.8-8.7)$ & 0.001 & $3.7(1.5-9.4)$ & 0.01 \\
\hline Focal resection & 26 & $0.7(0.2-2.1)$ & 0.49 & & $\mathrm{n} / \mathrm{s}$ \\
\hline PAS Grading & & & 0.005 & & 0.001 \\
\hline Grade of invasion 2 (reference) & 79 & & & & \\
\hline Grade of invasion 3 & 62 & $1.5(0.7-3.2)$ & 0.31 & $0.6(0.2-1.6)$ & 0.28 \\
\hline Grade of invasion 4 & 123 & $0.6(0.3-1.3)$ & 0.17 & $0.4(0.1-0.9)$ & 0.04 \\
\hline Grade of invasion 5 & 48 & $1.8(0.8-4.1)$ & 0.14 & $1.1(0.4-3.1)$ & 0.91 \\
\hline Grade of invasion 6 & 26 & $2.7(1.0-7.3)$ & 0.04 & $3.4(0.9-12.3)$ & 0.06 \\
\hline Oxytocin & & & 0.25 & & \\
\hline No oxytocin (reference) & 156 & & & & \\
\hline Prophylactic oxytocin & 113 & $0.8(0.4-1.3)$ & 0.32 & & $\mathrm{n} / \mathrm{i}$ \\
\hline Tranexamic acid & & & 0.001 & & \\
\hline No tranexamic acid (reference) & 182 & & & & \\
\hline Prophylactic tranexamic acid & 53 & $0.5(0.2-1.2)$ & 0.12 & & $\mathrm{n} / \mathrm{i}$ \\
\hline Therapeutic tranexamic acid & 95 & $2.4(1.4-4.2)$ & 0.001 & & $n / i$ \\
\hline Urgency of cesarean delivery & & & 0.05 & & 0.82 \\
\hline $\begin{array}{l}\text { At a time to suit the woman and maternity team (elective, } \\
\text { reference) }\end{array}$ & 228 & & & & \\
\hline Needing early delivery but no maternal or fetal compromise & 44 & $0.8(0.4-1.9)$ & 0.64 & $0.8(0.3-2.0)$ & 0.63 \\
\hline $\begin{array}{l}\text { Maternal or fetal compromise which is not immediately } \\
\text { life-threatening }\end{array}$ & 50 & $1.8(0.9-3.9)$ & 0.11 & $1.1(0.4-3.1)$ & 0.78 \\
\hline Immediate threat to life of woman or fetus (crash) & 15 & $3.5(1.2-10.2)$ & 0.02 & $1.6(0.4-6.3)$ & 0.48 \\
\hline Grade of surgeon & & & 0.001 & & 0.01 \\
\hline Specialist in PAS (reference) & 249 & & & & \\
\hline No specialist & 76 & $2.6(1.5-4.4)$ & 0.001 & $3.0(1.4-6.4)$ & 0.01 \\
\hline Position of uterine incision & & & 0.83 & & \\
\hline Lower transverse (reference) & 98 & & & & $\mathrm{n} / \mathrm{i}$ \\
\hline Fundal & 157 & $1.0(0.6-1.8)$ & 0.07 & & $\mathrm{n} / \mathrm{i}$ \\
\hline Transverse above placenta & 68 & $1.2(0.6-2.5)$ & 0.62 & & $\mathrm{n} / \mathrm{i}$ \\
\hline
\end{tabular}

(Continues) 


\begin{tabular}{|c|c|c|c|c|c|}
\hline \multirow{2}{*}{ Variable } & \multirow{2}{*}{$\begin{array}{l}N \text { (total } \\
n=338 \text { ) }\end{array}$} & \multicolumn{4}{|c|}{ Blood loss $>3500 \mathrm{ml}$ (75. P.) } \\
\hline & & \multicolumn{2}{|l|}{ Univariate analysis } & \multicolumn{2}{|c|}{ Multivariate analysis } \\
\hline Intravascular balloon & & & 0.70 & & \\
\hline Therapeutic & 4 & $\mathrm{n} / \mathrm{a}$ & 0.97 & & $n / i$ \\
\hline Pelvic arterial embolization & & & 0.68 & & \\
\hline No embolization (reference) & 319 & & & & \\
\hline Prophylactic & 2 & $0.8(0.2-3.1)$ & 0.83 & & $n / i$ \\
\hline Prophylactic & 1 & 0 (n/a) & 0.94 & & $n / i$ \\
\hline Therapeutic & 16 & $2.4(0.9-6.9)$ & 0.10 & & $\mathrm{n} / \mathrm{i}$ \\
\hline Internal iliac artery ligation & & & 0.03 & & \\
\hline No ligation (reference) & 328 & & & & \\
\hline Prophylactic & 0 & & $\mathrm{n} / \mathrm{a}$ & & $\mathrm{n} / \mathrm{i}$ \\
\hline Therapeutic & 10 & $4.4(1.2-16.7)$ & 0.03 & & $\mathrm{n} / \mathrm{i}$ \\
\hline Intrauterine balloon & & & 0.04 & & \\
\hline No balloon (reference) & 289 & & & & \\
\hline Prophylactic & 9 & $0.4(0.0-3.0)$ & 0.35 & & $n / i$ \\
\hline
\end{tabular}

Note: Data presented as odds ratio $(95 \% \mathrm{Cl})$. Statistically significant $p$ values $(<0.05)$ are written in bold.

Abbreviations: HE, hysterectomy; $n / a$, not available; $n / i$, not included in multivariate analysis; $n / s$, not significant; PAS, placenta accreta spectrum.

whereas deep invasion is associated with bleeding risk from extensive neovascularization. Our data clearly demonstrate the need for availability of blood products, no matter what the degree of anticipated invasion. Surgical vigilance, prompt hemorrhage control and early correction of coagulopathy are paramount in all cases.

The data clearly show that experience matters. The presence of a senior surgeon with expertise in the management of PAS showed the strongest correlation with reduced odds of blood loss $>3500$ and $>5500 \mathrm{ml}$. The risk for blood loss $>3500$ and $>5500 \mathrm{ml}$ did not vary among centers, even though over this study period, each center followed local protocols, rather than a single, standardized treatment guideline. The importance of an experienced team is consistent with findings of others and underscores the importance of timely referral of patients to a PAS center where an experienced, multidisciplinary team is available. ${ }^{23}$ We observed a trend toward less maternal blood loss over time during the study period, suggestive of a learning curve among participating centers.

This study provides insight into the actual treatment rendered across multiple, international referral centers within the International Society of Placenta Accreta Spectrum (IS-PAS) over a 12-year epoch. As a (partly retrospective) analysis of a contemporaneously collected cohort, it includes the limitations inherent with such an analysis.
All participating centers are in high-resource settings and have established PAS treatment teams, therefore, our results may not be generalizable to centers in low-income countries or without multidisciplinary team care. There was no standardized way to measure or estimate peripartum blood loss, which we tried to account for, using multilevel regression analysis. The extent of placental invasion was graded using the system available grading system at the time, ${ }^{7,8}$ which differs slightly compared with the FIGO grading system, specifically in the differentiation between placenta accreta and increta. As with any grading system, it is possible that different centers assigned these grades slightly differently between cases; however, we believe that the use of a standardized grading system based on clinical criteria at the time of delivery is far more accurate than the use of a system of descriptors based solely on pathologic evaluation, which inherently cannot take into consideration the appearance of tissues and structures when the placenta and uterus remain in vivo and excludes cases managed expectantly. Another way to classify placenta accreta spectrum is to categorize its topography depending on the blood supply. ${ }^{14,24}$ Topographic placental invasion has been shown to correlate with intraoperative blood loss. ${ }^{14}$ As topographic classifications have not been endorsed by the IS-PAS or FIGO, our case reporting form does not include topographic information, and 
TAB LE 3 Multilevel logistic regression analysis of maternal peripartum blood loss $>5500 \mathrm{ml}$

\begin{tabular}{|c|c|c|c|c|c|}
\hline Variable & $\begin{array}{l}n \text { (total } \\
n=338)\end{array}$ & \multicolumn{4}{|c|}{ Blood loss $>5500 \mathrm{ml}$ (90. P.) } \\
\hline Number of previous cesarean deliveries & 338 & $0.9(0.7-1.3)$ & 0.60 & & $\mathrm{n} / \mathrm{i}$ \\
\hline Operative management & & & 0.049 & & 0.01 \\
\hline Planned cesarean hysterectomy (reference) & 182 & & & & \\
\hline Unplanned cesarean hysterectomy & 40 & $2.9(1.1-7.5)$ & 0.03 & $2.4(0.9-6.6)$ & 0.08 \\
\hline Focal resection & 26 & $0.6(0.1-3.0)$ & 0.52 & $1.3(0.3-6.3)$ & 0.73 \\
\hline PAS grading & & & 0.02 & & 0.002 \\
\hline Grade of invasion 2 (reference) & 79 & & & & \\
\hline Grade of invasion 3 & 62 & $0.8(0.3-2.5)$ & 0.71 & $0.3(0.1-0.9)$ & 0.03 \\
\hline Grade of invasion 4 & 123 & $0.2(0.1-1.8)$ & 0.03 & $0.2(0.1-0.8)$ & 0.01 \\
\hline Grade of invasion 5 & 48 & $1.0(0.3-3.3)$ & 0.95 & $0.3(0.1-1.2)$ & 0.09 \\
\hline Grade of invasion 6 & 26 & $2.5(0.7-8.4)$ & 0.14 & $1.9(0.6-7.0)$ & 0.32 \\
\hline Oxytocin & & & 0.09 & & \\
\hline No oxytocin (reference) & 156 & & & & \\
\hline Prophylactic oxytocin & 113 & $0.9(0.4-2.5)$ & 0.91 & & $\mathrm{n} / \mathrm{i}$ \\
\hline Tranexamic acid & & & 0.45 & & \\
\hline No tranexamic acid (reference) & 182 & & & & \\
\hline Prophylactic tranexamic acid & 53 & $0.3(0.1-1.5)$ & 0.14 & & $\mathrm{n} / \mathrm{i}$ \\
\hline Therapeutic tranexamic acid & 95 & $1.0(0.4-2.4)$ & 0.93 & & $\mathrm{n} / \mathrm{i}$ \\
\hline Urgency of cesarean delivery & & & 0.05 & & 0.55 \\
\hline $\begin{array}{l}\text { At a time to suit the woman and maternity team (elective, } \\
\text { reference) }\end{array}$ & 228 & & & & \\
\hline Needing early delivery but no maternal or fetal compromise & 44 & $0.3(0.0-2.1)$ & 0.20 & $0.4(0.1-1.8)$ & 0.23 \\
\hline $\begin{array}{l}\text { Maternal or fetal compromise which is not immediately } \\
\text { life-threatening }\end{array}$ & 50 & $2.6(1.0-6.8)$ & 0.04 & $1.4(0.5-4.1)$ & 0.53 \\
\hline Immediate threat to life of woman or fetus (crash) & 15 & $2.7(0.7-11.2)$ & 0.16 & $0.9(0.2-3.8)$ & 0.85 \\
\hline Grade of surgeon & & & 0.001 & & 0.003 \\
\hline Specialist in PAS (reference) & 249 & & & & \\
\hline No specialist & 76 & $4.3(1.9-10.0)$ & 0.001 & $4.0(1.6-9.9)$ & 0.003 \\
\hline Position of uterine incision & & & 0.17 & & \\
\hline Lower transverse (reference) & 98 & & & & $\mathrm{n} / \mathrm{i}$ \\
\hline Fundal & 157 & $0.4(0.1-1.0)$ & 0.06 & & $\mathrm{n} / \mathrm{i}$ \\
\hline Transverse above placenta & 68 & $0.8(0.3-2.0)$ & 0.56 & & $\mathrm{n} / \mathrm{i}$ \\
\hline
\end{tabular}


TABLE 3 (Continued)

\begin{tabular}{|c|c|c|c|c|c|}
\hline \multirow{2}{*}{ Variable } & \multirow{2}{*}{$\begin{array}{l}n \text { (total } \\
n=338 \text { ) }\end{array}$} & \multicolumn{4}{|c|}{ Blood loss >5500 ml (90. P.) } \\
\hline & & \multicolumn{2}{|l|}{ Univariate analysis } & \multicolumn{2}{|l|}{ Multivariate analysis } \\
\hline Intravascular balloon & & & 0.17 & & \\
\hline Therapeutic & 4 & $0.7(0.2-2.4)$ & 0.61 & & $n / i$ \\
\hline Pelvic arterial embolization & & & 0.60 & & \\
\hline No embolization (reference) & 319 & & & & \\
\hline Prophylactic & 2 & $2.4(0.2-26.5)$ & 0.48 & & $n / i$ \\
\hline Prophylactic & 1 & $\mathrm{n} / \mathrm{a}$ & 0.98 & & $n / i$ \\
\hline Therapeutic & 16 & $1.9(0.4-9.2)$ & 0.45 & & $n / i$ \\
\hline Internal iliac artery ligation & & & 0.20 & & \\
\hline No ligation (reference) & 328 & & & & \\
\hline Prophylactic & 0 & & $\mathrm{n} / \mathrm{a}$ & & $n / i$ \\
\hline Therapeutic & 10 & $3.1(0.6-16.9)$ & 0.20 & & $n / i$ \\
\hline Intrauterine balloon & & & 0.02 & & \\
\hline No balloon (reference) & 289 & & & & \\
\hline Prophylactic & 9 & $\mathrm{n} / \mathrm{a}$ & 0.99 & & $n / i$ \\
\hline
\end{tabular}

Note: Data presented as odds ratio $(95 \% \mathrm{Cl})$. Statistically significant $p$ values $(<0.05)$ are written in bold.

Abbreviations: HE, hysterectomy; $n / a$, not available; $n / i$, not included in multivariate analysis; $n / s$, not significant; PAS, placenta accreta spectrum.

therefore such an analysis of the existing cases is not feasible. The analysis of perioperative arterial occlusion is limited by low case numbers, regional availability of such interventions; because these measures are frequently used in escalation and response to active bleeding, rather than prophylaxis, correlation with high blood loss is also possibly confounded by reversed causation. As the cohort included only patients with uterine or internal iliac artery ligation, the impact of ligation of other pelvic arteries was not evaluated. Due to the partly retrospective design, our data do not allow us to conclude that non-significant variables have no association with blood loss, especially for variables that may be underpowered. Such questions would ideally be answered through well-designed randomized controlled trials.

\section{5 | CONCLUSION}

Even PAS with low degrees of invasion (IS-PAS Grades 2 and 3) was associated with high peripartum blood loss. Blood loss could not be accurately predicted by the anticipated degree of placental invasion. No correlation of adjunctive measures or prior knowledge of clinical aspects such as the number of previous cesarean deliveries, the presence of placenta previa or antenatally diagnosed PAS with the incidence of high peripartum blood loss could be shown in our cohort. For PAS (IS-PAS Grades 2-6), lower blood loss was equally observed during planned hysterectomies and planned focal resections. The incidence of high blood loss was lowest when patients were treated by surgeons specialized in PAS. Well-designed and appropriately powered studies to address the safety and efficacy of adjunctive measures are essential to understand their utility.

\section{CONFLICT OF INTEREST}

Karin A Fox received funds from: an SMFM/Banner Health honorarium for participation in an annual critical care obstetrics course; Symposia Medicus - honorarium for educational lectures in high risk obstetrics; Wolters Kluwer - honorarium for UpToDate chapter authorship; and an NICHD R01 grant paid to her institution Molecular and Vascular MRI of Placenta Accreta Spectrum. None of the other authors has any conflicts of interest to declare.

\section{ORCID}

Alexander Schwickert (D) https://orcid.org/0000-0003-2360-6016

Heleen J. van Beekhuizen (D) https://orcid.org/0000-0001-8899-7412

Charline Bertholdt (D) https://orcid.org/0000-0001-9297-5363 
Karin A. Fox (D) https://orcid.org/0000-0002-8405-772X

Olivier Morel (D) https://orcid.org/0000-0001-6359-1328

Marcus J. Rijken (D) https://orcid.org/0000-0003-0914-5508

Vedran Stefanovic (D) https://orcid.org/0000-0001-5230-1698

Gita Strindfors (D) https://orcid.org/0000-0002-8780-6757

Alexander Weichert (D) https://orcid.org/0000-0001-5131-7372

Katharina Weizsaecker (D) https://orcid.org/0000-0002-9160-8315

Thorsten Braun (D) https://orcid.org/0000-0002-1989-9920

\section{REFERENCES}

1. Reale SC, Easter SR, Xu X, Bateman BT, Farber MK. Trends in postpartum hemorrhage in the United States From 2010 to 2014. Anesth Analg. 2020;130:e119-e122.

2. Jauniaux E, Hussein AM, Fox KA, Collins SL. New evidencebased diagnostic and management strategies for placenta accreta spectrum disorders. Best Pract Res Clin Obstet Gynaecol. 2019;61:75-88.

3. Jauniaux E, Jurkovic D. Placenta accreta: pathogenesis of a 20th century iatrogenic uterine disease. Placenta. 2012;33:244-251.

4. Collins SL, Alemdar B, van Beekhuizen HJ, et al. Evidence-based guidelines for the management of abnormally invasive placenta: recommendations from the International Society for Abnormally Invasive Placenta. Am J Obstet Gynecol. 2019;220:511-526.

5. Mehrabadi A, Hutcheon JA, Liu S, et al. Contribution of placenta accreta to the incidence of postpartum hemorrhage and severe postpartum hemorrhage. Obstet Gynecol. 2015;125:814-821.

6. van Beekhuizen HJ, Stefanovic V, Schwickert A, et al. A multicenter observational survey of management strategies in 442 pregnancies with suspected placenta accreta spectrum. Acta Obstet Gynecol Scand. 2021. https://doi.org/10.1111/aogs.14096

7. Collins SL, Stevenson GN, Al-Khan A, et al. Three-dimensional power Doppler ultrasonography for diagnosing abnormally invasive placenta and quantifying the risk. Obstet Gynecol. 2015;126:645-653.

8. Jauniaux E, Chantraine F, Silver RM, Langhoff-Roos J, FIGO Placenta Accreta Diagnosis and Management Expert Consensus Panel. FIGO consensus guidelines on placenta accreta spectrum disorders: epidemiology. Int J Gynaecol Obstet. 2018;140:265-273.

9. Braun T, van Beekhuizen HJ, Morlando M, Morel O, Stefanovic V, ISPAS. Developing a database for multicenter evaluation of Placenta Accreta Spectrum. Acta Obstet Gynecol Scand. 2021;100(Suppl. 1): 7-11.

10. Jauniaux E, Ayres-de-Campos D, Langhoff-Roos J, et al. FIGO classification for the clinical diagnosis of placenta accreta spectrum disorders. Int J Gynaecol Obstet. 2019;146:20-24.

11. Collins SL, Alemdar B, van Beekhuizen HJ, et al. Evidence-based guidelines for the management of abnormally invasive placenta recommendations from the International Society for Abnormally Invasive Placenta. Am J Obstet Gynecol. 2019;220:511-526.

12. Jauniaux E, Gronbeck L, Bunce C, Langhoff-Roos J, Collins SL. Epidemiology of placenta previa accreta: a systematic review and meta-analysis. BMJ Open. 2019;9:e031193.

13. Fitzpatrick KE, Sellers S, Spark P, Kurinczuk JJ, Brocklehurst $P$, Knight $M$. The management and outcomes of placenta accreta, increta, and percreta in the UK: a population-based descriptive study. BJOG. 2014;121:62-70; discussion 70-1.

14. Palacios-Jaraquemada JM, Fiorillo A, Hamer J, Martinez M, Bruno C. Placenta accreta spectrum: a hysterectomy can be prevented in almost $80 \%$ of cases using a resective-reconstructive technique. $J$ Matern Fetal Neonatal Med. 2020;26:1-8.

15. Sentilhes L, Ambroselli C, Kayem G, et al. Maternal outcome after conservative treatment of placenta accreta. Obstet Gynecol. 2010;115:526-534.
16. Sentilhes L, Kayem G, Ambroselli C, et al. Fertility and pregnancy outcomes following conservative treatment for placenta accreta. Hum Reprod. 2010;25:2803-2810.

17. Biele C, Kaufner L, Schwickert A, et al. Conservative management of abnormally invasive placenta complicated by local hyperfibrinolysis and beginning disseminated intravascular coagulation. Arch Gynecol Obstet. 2021;303:61-68.

18. Sentilhes L, Winer N, Azria E, et al. Tranexamic acid for the prevention of blood loss after vaginal delivery. N Engl J Med. 2018;379:731-742.

19. Ibrahim TH. Efficacy of tranexamic acid in reducing blood loss, blood and blood products requirements in Cesarian sections for patients with placenta accreta. Ain-Shams J Anesthesiol. 2019;11:31.

20. Chen L, Wang X, Wang H, Li Q, Shan N, Qi H. Clinical evaluation of prophylactic abdominal aortic balloon occlusion in patients with placenta accreta: a systematic review and meta-analysis. BMC Pregnancy Childbirth. 2019;19:30.

21. Shahin Y, Pang CL. Endovascular interventional modalities for haemorrhage control in abnormal placental implantation deliveries: a systematic review and meta-analysis. Eur Radiol. 2018;28:2713-2726.

22. Chen M, Liu X, You Y, et al. Internal iliac artery balloon occlusion for placenta previa and suspected placenta accreta: a randomized controlled trial. Obstet Gynecol. 2020;135:1112-1119.

23. Erfani H, Fox KA, Clark SL, et al. Maternal outcomes in unexpected placenta accreta spectrum disorders: single-center experience with a multidisciplinary team. Am J Obstet Gynecol. 2019;221(4):337.e1337.e5.

24. Palacios Jaraquemada JM, Bruno $\mathrm{CH}$. Magnetic resonance imaging in 300 cases of placenta accreta: surgical correlation of new findings. Acta Obstet Gynecol Scand. 2005;84:716-724.

\section{SUPPORTING INFORMATION}

Additional supporting information may be found online in the Supporting Information section.

How to cite this article: Schwickert A, Beekhuizen $\mathrm{HJ}$,

Bertholdt C, et al. Association of peripartum management and high maternal blood loss at cesarean delivery for placenta accreta spectrum (PAS): A multinational database study. Acta Obstet Gynecol Scand. 2021;100(Suppl. 1):29-40. https://doi. org/10.1111/aogs.14103

\section{APPENDIX 1}

Members of the International Society for Placenta Accreta Spectrum (IS-PAS) who contributed PAS cases and who are not listed as authors:

Pavel Calda, Department of Obstetrics and Gynaecology First Faculty of Medicine Charles University and General University Hospital in Prague, Czech Republic.

Kinga M. Chalubinski, Department of Obstetrics and Gynecology, Division of Obstetrics and Feto-Maternal Medicine, Medical University of Vienna, Vienna, Austria.

Frederic Chantraine, Department of Obstetrics and Gynecology, Centre Hospitalier Universitaire de Liège, site CHR Citadelle, Liège, Belgium. 
Sally Collins, Nuffield Department of Women's and Reproductive Health, University of Oxford, and the Fetal Medicine Unit, John Radcliffe Hospital, Oxford, UK.

Johannes J. Duvekot, Department of Obstetrics and Gynecology, Division of Obstetrics and Prenatal Medicine, Erasmus MC, University Medical Centre Rotterdam, Rotterdam, The Netherlands.

Lene Gronbeck, Department of Obstetrics, Rigshospitalet, Copenhagen University Hospital, Copenhagen, Denmark.

Wolfgang Henrich, Charité - Universitätsmedizin Berlin, corporate member of Freie Universität Berlin, Humboldt-Universität zu Berlin, and Berlin Institute of Health, Department of Obstetrics, Berlin, Germany.

Pasquale Martinelli, MD, Department of Neuroscience, Reproductive Sciences and Dentistry, University Federico II Naples, Naples, Italy.

Mina Mhallem Gziri, Department of Obstetrics, Cliniques Universitaires Saint-Luc, Brussels, Belgium.

Maddalena Morlando, MD, PhD, Department of Woman, Child and General and Specialized Surgery, Obstetrics and Gynecology
Unit, University of Campania "Luigi Vanvitelli", Naples, Italy and Department of Neuroscience, Reproductive Sciences and Dentistry, University of Naples Federico II, Naples, Italy.

Andreas Nonnenmacher, Charité - Universitätsmedizin Berlin, corporate member of Freie Universität Berlin, Humboldt-Universität zu Berlin, and Berlin Institute of Health, Department of Obstetrics, Berlin, Germany.

Jorma Paavonen, Department of Obstetrics and Gynecology, Helsinki University Hospital and University of Helsinki, Helsinki, Finland.

Petra Pateisky, Department of Obstetrics and Gynecology, Division of Obstetrics and Feto-Maternal Medicine, Medical University of Vienna, Vienna, Austria.

Philippe Petit, Department of Obstetrics and Gynecology, center Hospitalier Universitaire de Liège, site CHR Citadelle, Liège, Belgium.

Mariola Ropacka, Department of Perinatology and Gynecology, Poznan University of Medical Sciences, Poznan, Poland.

Minna Tikkanen, Department of Obstetrics and Gynecology, Helsinki University Hospital and University of Helsinki, Helsinki, Finland. 